\title{
Pruner Michel, L'analyse du texte de théâtre
}

\section{Fatima Pilone}

\section{(2) OpenEdition}

\section{Journals}

\section{Édition électronique}

URL : http://journals.openedition.org/studifrancesi/35477

DOI : 10.4000/studifrancesi.35477

ISSN : 2427-5856

\section{Éditeur}

Rosenberg \& Sellier

\section{Édition imprimée}

Date de publication : 1 novembre 2005

Pagination : 471

ISSN : 0039-2944

\section{Référence électronique}

Fatima Pilone, "Pruner Michel, L'analyse du texte de théâtre », Studi Francesi [En ligne], 146 (XLIX | II) | 2005, mis en ligne le 30 novembre 2015, consulté le 18 avril 2021. URL : http://

journals.openedition.org/studifrancesi/35477 ; DOI : https://doi.org/10.4000/studifrancesi.35477

Ce document a été généré automatiquement le 18 avril 2021.

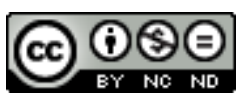

Studi Francesi è distribuita con Licenza Creative Commons Attribuzione - Non commerciale - Non opere derivate 4.0 Internazionale. 


\title{
Pruner Michel, L'analyse du texte de théâtre
}

\author{
Fatima Pilone
}

\section{RÉFÉRENCE}

PRUNER MICHEL, L'analyse du texte de théâtre, Paris, Nathan, coll. Université, 2001, pp. 128.

1 Maître de conférences d'études théâtrales all'Università Lumière-Lyon II, Michel PRUNER accompagna il lettore nell'analisi del testo teatrale.

2 Sin dalla prefazione, l'autore sottolinea la difficoltà del districarsi nello studio dei testi di teatro, proprio per l'essenza stessa del teatro, che si vuole «arte dell'istante, quindi della morte», opponendosi a qualunque altro testo, che si iscrive invece nella durata. ̀̀ questo il primo paradosso: uno scritto, che con caratteri stampati fissa ciò che è destinato in realtà ad esprimersi nel movimento e nella rappresentazione. Il testo teatrale è in grado infatti di esprimersi nella sua totalità solo se proiettato sulla scena. Per questo, esso ha bisogno di tutta una serie di segni non verbali, indicazioni per gli attori, i registi, gli scenografi.

3 Molti sono tuttavia gli elementi, tipici di un componimento scritto, che consentono di svelare anche i segreti di un testo teatrale, a cominciare dal titolo, che ha la triplice funzione di identificare l'opera, di informare sul suo contenuto, di attirare l'attenzione. Spesso di seguito ad esso, il genere, codificato, che fornisce al lettore riferimenti impliciti ed immediati sulla natura dell'opera.

4 In epoca antica, $i$ testi teatrali erano sovente preceduti da un argument, una sorta di riassunto della pièce; questa tradizione è stata ripresa in quasi tutte le epoche: da quella classica, all'utilizzo monumentale che se ne fece in epoca romantica, fino ad arrivare al XX secolo.

5 I due aspetti inscindibili del testo di teatro sono tuttavia il dialogo e le didascalie; è questo il dualismo che costituisce la sua specificità. Nel primo, l'autore si nasconde dietro la parola che presta alle proprie creature. È il dialogo il modo di espressione 
drammatico per eccellenza. Il dialogo teatrale ha sempre due destinatari: l'autore si rivolge al pubblico, mentre i suoi personaggi si parlano tra di loro. Con le didascalie, invece, l'autore si esprime direttamente, fornendo indicazioni fondamentali relative ai personaggi, al luogo ed al tempo dell'azione, aiutando quel testo scritto a farsi parola.

Frutto di questo dualismo sono lo spazio scenico, quello reale dove spettatori ed attori vengono in contatto, e lo spazio drammaturgico, destinato a prender forma a seconda dei criteri estetici del regista e dello scenografo.

7 A livello temporale, lo spettacolo è il coesistere di due temporalità che si sovrappongono, senza tuttavia mai confondersi: il tempo della rappresentazione, ovvero la durata vissuta dallo spettatore, ed il tempo della fiction. E andare a teatro è proprio entrare in uno spazio temporale diverso da quello quotidiano, in un luogo dove i personaggi si incarnano negli attori, e non viceversa.

8 Anche privato della rappresentazione, il testo teatrale conserva dunque la sua potenza poetica e lorsque se sont évanouis les prestiges de la reprèsentation, il attend dans une bibliothèque de les ressusciter quelque jour. 